\title{
Percursos Formativos no Campo da Extensão: obra cinematográfica como dispositivo para o diálogo
}

\author{
Caminos formativos en el campo de la extensión: el trabajo \\ cinematográfico como dispositivo para el diálogo
Formative Paths in the Field of Extension: cinematographic work as a device for dialogue

\author{
Jarbas Parise Moscato ${ }^{1}$ \\ Helena Beatriz da Costa de Oliveira ${ }^{2}$ \\ Paula Bianchi ${ }^{3}$ \\ Everton Fêrrêr de Oliveira ${ }^{4}$
}

Resumo

\begin{abstract}
Este trabalho faz a análise de uma atividade cinematográfica realizada no projeto de extensão Percursos Formativos no Campo da Extensão, proposto pelo Curso de Pedagogia, realizado no ano de 2017 na Universidade Federal do Pampa, Campus Jaguarão-RS-Brasil. A proposta da atividade foi feita pelo Programa de Educação Tutorial (PET) do Curso de Bacharelado em Produção e Política Cultural direcionado para os participantes de todos os cursos do Campus Jaguarão da UNIPAMPA e comunidade em geral. Os objetivos do projeto eram ampliar o contato e a prática da extensão universitária e com isso a inserção regional, para tanto foram convidados extensionistas de diferentes áreas. Neste trabalho analisamos a atividade por meio de trinta formulários de avaliação da atividade desenvolvida no projeto de extensão, pano de fundo e cenário dedicados à vivência dos participantes do projeto. Como discussões ressaltamos a proposta e a forma pedagógica instigante trazidas na atividade cinematográfica. Proporcionou-se olhar, escuta e interação no diálogo sobre o processo vivido pelos participantes de diferentes cursos. Como considerações finais destacamos que a atividade orientada pela arte do cinema possibilita abertura às inovações, tentativas de ampliação do leque para reflexões e observações da realidade e com isso problematizar tanto o dialogo proporcionado pela atividade cinematográfica.que motivou o debate entre os participantes envolvidos no referido projeto quanto a reflexão acadêmica pautada no cinema
\end{abstract}

Palavras-Chave: atividade cinematográfica, Extensão univeristária, universidade.

\section{Resumen}

Este artículo analiza una actividad cinematográfica realizada en el Proyecto de Extensión de Rutas de Capacitación en el Campo de Extensión, propuesto por el Curso de Pedagogía, realizado en 2017 en la Universidad Federal de Pampa, Campus Jaguarão-RS-Brasil. El propósito de la actividad fue realizado por el Programa de Educación Tutorial (PET) del Curso de Licenciatura en Producción y Política Cultural dirigido a los participantes de todos los cursos del Campus Jaguarão de UNIPAMPA y la comunidad en general. Los objetivos del proyecto fueron expandir el contacto y la práctica de la extensión universitaria y, por lo tanto, la inserción regional, para lo cual se invitó a extensionistas de diferentes áreas. En este artículo analizamos la actividad a través de treinta formas de evaluación de la actividad desarrollada en el proyecto de extensión, antecedentes y escenario dedicado a la experiencia de los participantes del proyecto. Como discusiones enfatizamos la propuesta y la forma pedagógica que provoca la reflexión que se produjo en la actividad

\footnotetext{
${ }^{1}$ Mestrando em Educação - Licenciatura pela Universidade Federal do Rio Grande. Professor da Rede municipal de Ensino de Jaguarão - RS. Equipe executora do Projeto.

${ }^{2}$ Bel em Política e Produção Cultural. Licenciada em artes Visuais UNOPAR e Especiallizanda em Metodologia do Ensino de Artes - UNOPAR, Unidade Jaguarão - RS. Equipe executora do Projeto

${ }^{3}$ Professora Dr. Adjunta do Programa de Pós Graduação em Educação PPGEdu e Curso de Pedagogia do

Campus Jaguarão da UNIPAMPA, Equipe executora do Projeto.

${ }^{4}$ Professor Msc. Adjunto do Curso de Pedagogia, Coordenador do Curso de Pedagogia/UAB. Coordenador Do Projeto.
} 
cinematográfica. Proporcionó una mirada, escucha e interacción en el diálogo sobre el proceso experimentado por los participantes de diferentes cursos. Como consideraciones finales, destacamos que la actividad orientada por el arte del cine permite la apertura a las innovaciones, intenta ampliar el rango de reflexiones y observaciones de la realidad y, por lo tanto, problematiza tanto el diálogo proporcionado por la actividad cinematográfica, que motivó el debate entre los participantes involucrados en el proyecto. sobre la reflexión académica basada en el cine. Palabras clave: actividad cinemática, extensión universitaria, universidad.

Keywords: cinematographic activity, university extension, university.

\section{Introdução}

Este trabalho retrata uma atividade pautada por uma obra cinematográfica. Pensada e executada pelo PET do Bacharelado em Produção e Política Cultural no projeto de extensão Percursos Formativos no Campo da Extensão, proposto pelos docentes do Curso de Pedagogia e Programa de Pós-Graduação em Educação (PPGEdu) na Universidade Federal do Pampa, Campus Jaguarão-RS-Brasil, direcionado para os participantes de todos os cursos e comunidade externa, a ação para os estudantes de graduação serviu para integralização de horas de complementares de graduação, ofertado no $1^{\circ}$ semestre de 2017 , para os demais a aproximação com a produção da extensão universitária. Neste ensaio analisamos uma das onze atividades propostas. Pois $\mathrm{O}$ uso da obra cinematográfica motivou o debate entre os participantes envolvidos no projeto e vimos nesta atividade uma forma potencial de realizar reflexões acerca da realidade.

Foi a apresentado um obra cinematográfica intitulado "Território do brincar" que, é um trabalho de pesquisa, documentação e sensibilização desenvolvido pelo Instituto Alana (https://alana.org.br/project/ciranda-de-obra cinematográficas/) que traz as formas de brincar das crianças de diferentes localidades do Brasil. A educadora Renata Meirelles e o documentarista David Reeks trabalharam em diversas comunidades rurais, indígenas, quilombolas, grandes metrópoles, localidades no sertão e no litoral, trazendo registros do brincar de crianças destes locais por onde passavam. Este obra cinematográfica foi usado como ferramenta para a construção de diálogo com os participantes.

A atividade com uso de uma obra cinematográfica foi desenvolvida no projeto de extensão e propôs troca de saberes entre os participantes, enriquecendo o diálogo, abrindo o olhar em relação as possibilidades de recursos audiovisuais, nos colocando em local onde cada indivíduo enxergou o brincar de forma livre e a importância do brincar na infância.

O Projeto Percursos Formativos no Campo da Extensão foi realizado no primeiro semestre de 2017, entre 01/04/2017 e final 15/07/2017 de promover a reflexão e formação acerca das práticas extensionistas e seus impactos no desenvolvimento institucional e regional. 


\section{Metodologia}

Foram analisados trinta formulários de avaliação da atividade executada, dedicados à conhecer dos participantes sua impressões. Para Minayo (1998) a pesquisa em ciências humanas têm se caracterizado pela necessidade de interpretação dos dados da realidade. Nossa participação no projeto nos trouxe a oportunidade de poder analisar o uso obra cinematográfica e sua avaliação no momento em que estava acontecendo, a interação e a integração que propiciou dialogar e entender as trocas naquele momento específico. A atividade foi desenvolvida no dia 17 de março de 2017, das 19:00 horas até 21:00 horas, no auditório do Campus Jaguarão da UNIPAMPA, ficamos de posse do material usado como avaliação da proposta, o que veio a ajudar nesta construção.

\section{Referencial teórico}

O cinema faz parte do cotidiano das pessoas e faz parte do dia a dia dos alunos. Freire (1996, p. 139) trazia a importância de colocarmos a televisão no ambiente escolar para gerar debates "o que se diz e o que se mostra e como se mostra na televisão me parece algo cada vez mais importante". E coloca que da mesma forma, pode ser usado o audiovisual, o cinema. Podendo ser usado como ferramenta didático-pedagógica para trabalhar temas transversais importantes para a formação do cidadão. De acordo com Piovesan, Barbosa e Costa, (2010, p. 1) os "obra cinematográficas possibilitam que o professor trabalhe vários conceitos, temas e significados utilizados na vida diária dos seus alunos".

Segundo Reia-Baptista (1995, p. 143) o cinema se insere nos estudos da área pedagógica dos obra cinematográficas e do cinema tornando-se um momento de adquirir conhecimentos e de abrir espaço para a reflexão crítica sobre uma peculiaridade dominante de nossa história cultural onde a humanidade vem deixando seus sinais narrativos e multiculturais em imagens e sons interligados de formas variadas.

Para Hernandez (1998) o trabalhar com projetos apresenta um novo ponto de vista para que possamos compreender o processo de ensino-aprendizagem. Aprender não é só memorizar, e ensinar não se restringe a simplesmente repassar conteúdos prontos. $\mathrm{O}$ autor nos traz a importância de trabalhar com projetos, destaca que o sujeito que trabalha com esta abordagem não apenas memoriza e repassa conteúdos, mas entende para poder dialogar durante o processo de troca de conhecimentos. Na atividade de exibição da obra cinematográfica se tornou claro o momento de troca de saberes sem um conhecimento préconcebido, instigando o diálogo espontâneo dos sujeitos envolvidos naquele estante na troca reciproca. 
De acordo com Lebourg e Fernandes (2016, p. 261) “[...] a Educação precisa ser repensada a partir de conhecimentos significativos que possibilitem um diálogo com a realidade por meio de posturas pedagógicas engajadas e reflexivas, o professor assume um papel fundamental em todo esse processo." Nos trazem a importância da construção de espaços direcionados que permitam as discussões e colaborações por meio do diálogo, ajudando a criar uma reflexão crítica através da proposta de atividades pedagógicas, neste sentido o obra cinematográfica exibido cumpriu seu papel.

Segundo Gomes (2007, p.33) "Não se trata de negar a importância do conhecimento escolar, mas abolir o equívoco histórico da escola e da educação de ter como foco prioritariamente os conteúdos e não os sujeitos dos processos educativos”. Este aspecto caminha junto com a visão de Freire (2014, p.47), quando nos coloca que o ato de ensinar não é reduzido a "transferir conhecimento, mas criar as possibilidades para sua própria produção ou a sua construção". Estes autores nos trazem a necessidade de abrir espaços e formas para que a construção dos saberes aconteça de forma dialógica entre os envolvidos nos processos de aprendizagem, fazendo com que estes sujeitos tragam suas colaborações durante o ato de adquirir conhecimentos. Este momento foi gerado através da apresentação da obra cinematográfica que foi passado na atividade proposta pelo grupo responsável por aquele momento.

Roveri e Soares (2015, p. 7) trazem a necessidade do brincar livre, "A partir disso, vale ressaltar a especificidade do trabalho dos profissionais de educação: seria importante que fizessem escolhas pedagógicas conscientes, buscando propostas que contemplassem o direito ao brincar desapegado dos apelos do consumismo." As autoras nos mostram como um profissional envolvido na área da educação tem que fugir do consumismo gerado pelo mercado e trazer propostas que gerem momentos em que o brincar livre seja alvo das suas atividades quando esteja no lugar de educador. Este momento foi bem proposto na escolha da obra cinematográfica onde trouxe o brincar em sua forma genuína, instigando o debate aos futuros docentes presentes no projeto.

\section{Resultados e discussões}

Ressaltamos que durante nossa investigação neste contexto, que a proposta e a forma pedagógica interessante e instigante trazidas na atividade cinematográfica proporcionaram um momento de interação e de diálogo dos participantes, provocando o interesse, procurando trabalhar a partir das demandas pedagógicas mostrando a cultura das crianças de diversas 
localidades do Brasil. A partir das transcrições dos formulários de avaliação destacamos o que segue na Tabela 1:

\section{\begin{tabular}{|l|l|l}
$17 / 03 / 2017$ & PET PPC & Novas formas de aprender brincando
\end{tabular}}

* O documentário trouxe a reflexão de como fazer a criança brincar e aprender. Por mais que as brincadeiras do documentário sejam algumas perigosas para desenvolver na escola, mas algumas eu já desenvolvi.

* A roda de conversa e o documentário foram produtivas e, com certeza, me fez refletir sobre práticas pedagógicas.

* Apesar de já ter assistido esse documentário adquiri, novos conhecimentos.

* Ótimo tema que foi proposto para este dia pois trouxe grandes reflexões e novos conhecimentos de até mesmo um outro ponto de vista sobre o brincar de uma criança.

* Gostei bastante do evento.

*A palestra nos trouxe uma nova visão do brincar. Acredito que é preciso ser trabalhado o brincar livre de maneira mais forte nas realidades das escolas.

* Importante por possibilitar-me novos conhecimentos.

* Momento maravilhoso, me abriu os olhos e me mostrou como é bom o brincar, sem ser o tal do brincar dirigido.

* O projeto PET é um projeto muito significante e seria interessante trazê-los mais vezes para que mostrem seu trabalho.

* Parabéns à palestrante, demonstrou domínio do assunto relacionando a vários assuntos devido aos comentários do grupo.

*Foi uma aula bem proveitosa.

* Muito bom o tema.

* Acredito que os palestrantes poderiam experimentar algumas brincadeiras.

* A palestra foi muito produtiva, ajudou para que nós percebamos a importância de deixar a criança criar seus brinquedos.

* Palestra que faz com que todos adquiram conhecimentos através de trocas de saber.

* É importante o assunto “o brincar” ser mais estudado e divulgado. As nossas crianças estão privadas de criarem, trazer o novo, invetar e principalmente brincar. A sociedade não entende que a escola não está propiciando o brincar como forma de desenvolvimento. A 
sociedade quer criar o adulto miniatura. E a escola também está se deixando levar pelo capitalismo e pelo consumismo. Dar a atividade pronta, gera menos tempo para educar e incentivar a criar, criticar, ser livre.

* Parabéns, que continuem assim, cada encontro uma nova aprendizagem.

* Foi desenvolvido ótimo debate.

* Palestrantes dedicadas e didáticas.

Tabela 1 - Transcrição das colaborações dos participantes. Fonte: Avaliações compiladas pelos autores

Notamos na tabela 1 a importância que os participantes atribuíram sobre o brincar livre, ressaltando os novos conhecimentos que estavam sendo apresentados, a possibilidade da troca de saberes durante a atividade, o momento em que a roda de conversa proporcionou um diálogo e a reflexão sobre a obra cinematográfica, sobre as práticas pedagógicas e a possibilidade de tirar o olhar das brincadeiras impostas pela sociedade baseada no mercado.

A atividade atendeu as expectativas pois trouxe a discussão a necessidade de se discutir este tema na sociedade, a e a importância do tema e a reflexão sobre o brincar que é um tema esquecido nos dias de hoje frente a cultura cyber. Além disso, estruturar a atividade numa roda de conversa possibilitou uma maior inserção dos participantes para manifestação de suas compreensões.

Para ilustrar as avaliações apresentamos abaixo a ficha de avaliação quantificadas as respostas:

\begin{tabular}{|c|c|c|c|c|c|}
\hline & ÓTIMO & BOM & REGULAR & RUIM & PÉSSIMO \\
\hline $\begin{array}{l}\text { Como você classifica sua } \\
\text { satisfação com este evento? }\end{array}$ & 24 & 10 & 1 & & \\
\hline $\begin{array}{l}\text { Habilidade de apresentação do } \\
\text { palestrante }\end{array}$ & 22 & 11 & 2 & & \\
\hline Conhecimentos do palestrante & 16 & 17 & & & \\
\hline Divulgação do evento & 10 & 12 & 12 & 1 & \\
\hline Carga horária & 20 & 12 & 3 & & \\
\hline $\begin{array}{l}\text { Aquisição de novos } \\
\text { conhecimentos }\end{array}$ & 20 & 12 & 3 & & \\
\hline $\begin{array}{l}\text { Infraestrutura ( auditório, recursos } \\
\text { visuais, etc...) }\end{array}$ & 19 & 15 & 1 & & \\
\hline
\end{tabular}


Na tabela 2, notamos que uma maioria que classificou o evento como ótimo e bom em se tratando de satisfação com o evento, tendo menos incidência as opções regular e péssimo, uma maioria classificou como ótimo e bom. No quesito habilidades dos palestrantes houveram manifestações de regular, mas em sua maioria classificou como ótimo e bom os conhecimentos dos palestrantes. Na divulgação do evento foi classificado como ótimo e bom.

\section{Conclusões}

Como conclusões trazemos a importância da reflexão acerca dos diferentes objetos culturais que permeiam nosso entorno, especialmente aqueles que trazem significados sobre a constituição e as aprendizagens desde a infância, aqui, em tela uma obra cinematográfica inspirada nas infâncias.

Não podemos perder o horizonte da sociabilidade, isto permite que as rodas de conversas estimulem os diferentes olhares dos diferentes participantes. Como este espaço proporcionado por um projeto de extensão universitária que reuniu graduandos de diferentes cursos e outros sujeitos, sejam eles cursistas ou formadores. A exemplo da atividade em evidência contamos com acadêmicos bacharelandos de política e produção cultural, a convivência compartilhada que o projeto nos possibilitou foi possível observar nas trocas de conhecimentos geradas no momento de diálogo sobre a temática colocada na atividade e nos encaminhando durante as aprendizagens mútuas.

Para além da integralização curricular de horas complementares de extensão para os participantes e formadores da graduação a possibilidade de estarem inseridos em um espaço que proporciona ideias para serem usadas em sala de aula, em novas atividades, complementando teorias estudadas dentro na universidade, enriquecendo o perfil destes participantes que se tornam mais a tais questões. Sabemos que se torna necessário que estes participantes criem o habito de estudar, pesquisar, analisar, buscar outras obras cinematográficas para serem usados em novas propostas durante sua formação docente.

Colocamos a importância de nossa atuação na implementação desta atividade com a obra cinematográfica, ressaltando as possibilidades de aprendizagem, salientando que estes participantes têm a necessidade de estarem abertos as inovações, tentativas, observações para poder construir junto com os demais profissionais que estarão nos espaços profissionais conhecimentos advindos da socialização e de integração de diferentes áreas presentes, especialmente, na universidade. 


\section{Referências}

HERNÁNDEZ, Fernando. Repensar a função da escola a partir dos projetos de trabalho. Revista Pátio, Ano 2, n. 6, p. 27-31, ago./ out. 1998.

FREIRE, Ana Maria Araújo. Apresentação. 2014. In: FREIRE, Paulo. Pedagogia dos sonhos possíveis. São Paulo: Paz e Terra, 2014.

FREIRE, Paulo. Pedagogia da autonomia. São Paulo: Paz e Terra, 1996 (Coleção Leitura).

GOMES, Alberto Albuquerque. Usos e possibilidades do grupo focal e outras alternativas metodológicas. Eccos Revista Científica, São Paulo: UNINOVE, v. 7; n. 2. jul./dez., 2005. Disponível em: https://philpapers.org/rec/GOMUEP. Acesso em: 31 out. 2017.

LEBOURG, Elodia Honse; FERNANDES, Valdete Aparecida. O copo meio cheio: a rede como um campo de possibilidades de valorização de professores. Texto Livre: Linguagem e Tecnologia, v. 9, n. 2, p. 254-262, 2016. Disponível em: http://www.periodicos.letras.ufmg.br/index.php/textolivre/article/view/10975/9822. Acesso em: 27 out. 2017.

MINAYO, Maria Cecilia et all. Pesquisa Social: teoria, método e criatividade. Petrópolis: Vozes, 1998.

REIA-BAPTISTA, Vítor. Pedagogia da comunicação, cinema e ensino: dimensões pedagógicas do cinema. In: ALMENARA, Julio Cabero; GÓMEZ, José Ignacio Aguaded (Coord.). Educación y medios de comunicación en el contexto iberoamericano. Andalucia: Universidad Internacional de Andalucía, 1995. p. 143-155. Disponível em: https://sapientia.ualg.pt/handle/10400.1/9120 Acesso em: 15 out. 2017.

ROVERI, Fernanda Theodoro; SOARES, Carmen Lúcia. Compre, colecione e fique na moda: reflexões sobre o consumismo infantil e o brincar. Zero-a-Seis, v. 17, n. 31, p. 3-14, 2015. Disponível em https://periodicos.ufsc.br/index.php/zeroseis/article/view/19804512.2015n31p3 Acesso em: 10 out. 2017.

Portal da obra cinematográfica "Território do brincar". Disponível em: http://territoriodobrincar.com.br/territorio-do-brincar-na-midia/obra cinematográficaterritorio-brincar/. Acesso em: 2 out. 2017.

PIOVESAN, Angélica; BARBOSA, Lívia; COSTA, Sara Bezerra. Cinema e Educação. In: SIMPÓSIO REGIONAL DE EDUCAÇÃO/COMUNICAÇÃO, 1., 2010, Aracaju. Anais... Aracaju: Colóquio EAD comunicação, 2010. 